\title{
Design of universal H-bridge converter for cascaded multilevel topologies
}

\author{
Zdenek Kehl \\ Department of Power Electronics and \\ Machines \\ University of West Bohemia \\ Pilsen, Czech Republic \\ kehlz@fel.zcu.cz
}

\author{
Tomas Glasberger \\ Department of Power Electronics and \\ Machines \\ University of West Bohemia \\ Pilsen, Czech Republic \\ tglasber@fel.zcu.cz
}

\author{
Luboš Streit \\ Department of Power Electronics and \\ Machines \\ University of West Bohemia \\ Pilsen, Czech Republic \\ lloyd@fel.zcu.cz
}

\begin{abstract}
A new universal multi H-bridge converter is introduced in this paper. The main purpose of proposed universal converter is simple testing of modular multilevel topologies as CHB and M2LC topology. The whole converter is designed to fit a standard $2 \mathrm{U}$ height 19" rack mount enclosure. The converter consists of four $5 \mathrm{~kW}$ power cards with H-bridge IGBT modules. There are front and back panels in the converter construction dedicated to connecting a control unit, necessary quantities signaling, and enabling different and modular topology configurations using power terminals interconnection. The converter is also equipped with inevitable protections and measurements.
\end{abstract}

Keywords-converter, modular, H-bridge, design, IGBT, printed circuit board, CAN, measurement

\section{INTRODUCTION}

Nowadays, the multilevel converters are very spread in medium voltage and/or high power applications. Especially modular multilevel topologies as cascaded $\mathrm{H}$-bridge topology (CHB) or modular multilevel topology (M2LC) are often used in applications as HVDC, MVDC, STATCOMs and UPS systems [1]-[6]. These topologies bring advantages like low harmonic distortion of the output voltage waveform and low current ripple. There is also lower voltage stress of power switches, and reduced losses due to lower switching frequency in comparison with standard two level voltage source converters. The main advantage of CHB and M2LC topology is the modularity, that is reached by connecting H-Bridge or half-bridge cells in cascade. It allows simply modification of topology, and quite fast and easy repairability in real applications [3], [7].

The control algorithms for multilevel converters, especially for modular multilevel topologies, are usually very complex. These algorithms need a large number of measured signals which are necessary for computing of proper control steps [1]. For example, in case of STATCOM application these algorithms must ensure balancing of dc-link capacitors voltages and generating of suitable current waveform into the power grid [2], [9]. For optimal function of the control algorithm, all dc-link voltages, all compensation currents, all grid voltages and all grid currents have to be measured. It leads to extensive hardware conception, which must be equipped with a sufficient number of sensors, peripherals, binary inputs and outputs and so on [5].

This paper describes a new universal multi H-bridge converter which is called SHRack (Smart H-bridge Rack). The SHRack was proposed for fast design and testing modular multilevel topologies and for enhancement of control algorithms design possibilities. The proposed non-standard conception of the converter brings some useful features, which facilitate building stands and testing different modular multilevel topologies.

\section{CONVERTER CONCEPTION}

The SHRack converter consist of four main parts: power blocks, driver modules, front panel board and back panel board. The four power and driver boards are located on an air forced heatsink. The power outputs are situated on the back panel. These parts together represents a power part of SHRack converter. Front panel creates interface for an user and/or for an external control unit. Among other things, a necessary power supply for the individual electronic modules is implemented in the rack enclosure too.

\section{A. Power block}

The power blocks are main functional parts of the proposed converter. One power block consists of SEMIKRON SK50GH12T4T power semiconductor module, dc-link capacitors and measurements. The power semiconductor module is based on Trench 4 IGBT technology. The absolute maximum ratings are $1200 \mathrm{~V} \mathrm{dc}$ voltage and $50 \mathrm{~A} \mathrm{dc}$ current. The temperature sensor is also integrated in the IGBT module. Fig. 1. shows the designed power block without the heatsink.

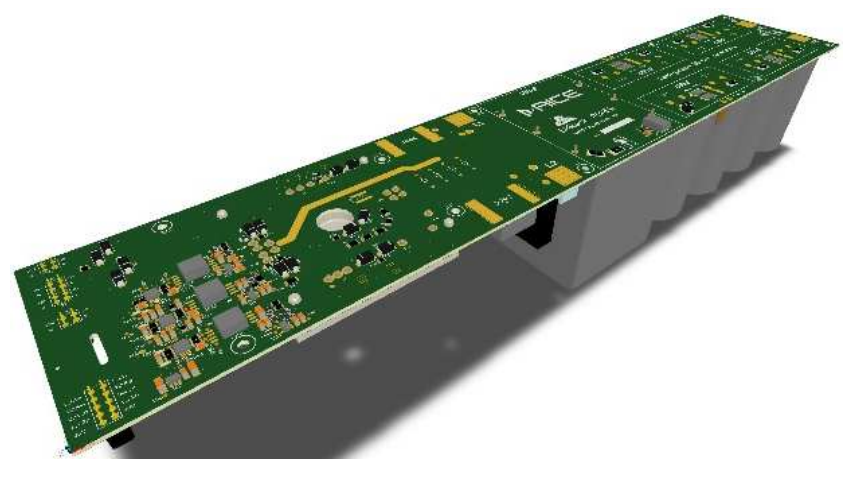

Fig. 1. Power block

The dc-link is formed by a bank of electrolytic capacitors and one polypropylene capacitor (Fig. 2). The polypropylene capacitor $\left(\mathrm{C}_{\mathrm{PP}}\right)$ is located as close to the IGBT module as possible. This capacitor is used as snubber capacitor due to its parameters as low equivalent series resistance $(\mathrm{ESR}=3.5$ $\mathrm{m} \Omega)$, low equivalent series inductance $(\mathrm{ESL} \approx 31 \mathrm{pH})$ and high ripple current capability $\left(25 \mathrm{~A}_{\mathrm{rms}} / 10 \mathrm{kHz}\right)$. The electrolytic capacitors $\left(\mathrm{C}_{1}-\mathrm{C}_{8}\right)$ are in the serial-parallel connection to achieve required capacity and sufficient voltage of the dc-link. The dc-link capacitors are balanced by a 
network of resistors (it is not shown in Fig. 2 for better clarity). There are implemented power jumpers J1-J4 that enable disconnecting a selected group of serial capacitors. The capacity of one power block can be according to Fig. 2: 100 $\mu \mathrm{F} ; 700 \mu \mathrm{F} ; 1.3 \mathrm{mF} ; 1.8 \mathrm{mF}$ or maximum of $2.5 \mathrm{mF}$. The maximum operational dc-link voltage is $\mathrm{U}_{\mathrm{DC}}=750 \mathrm{~V}$.

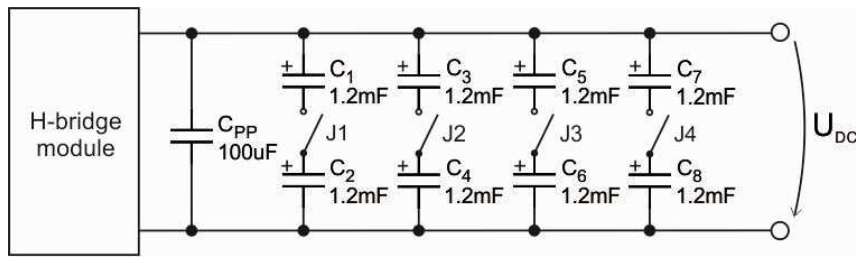

Fig. 2. Dc-link block scheme

An OptoMOS relay of discharging resistor is implemented in the power board PCB. Each power block has a discharging resistor which is located on the heatsink. If the power supply is turned on, the discharge circuits are open, and discharging resistors are disconnected. If the power supply is turned off, the discharge circuits are closed, and the discharging resistors are parallel to the dc-link. It is necessary for quick and safe discharge of the dc-link capacitors bank.

Each power block is equipped with important measurement modules. The measurement modules are based on insulated amplifiers with differential outputs. A fully differential amplifier further amplifies the differential outputs to achieve a higher signal to noise ratio (SNR). The dc-link voltage, IGBT module temperature, and currents at both H-bridge power outputs are measured (see Fig. 3). All measured signals are led to the front panel connectors and a microprocessor (see par. C).

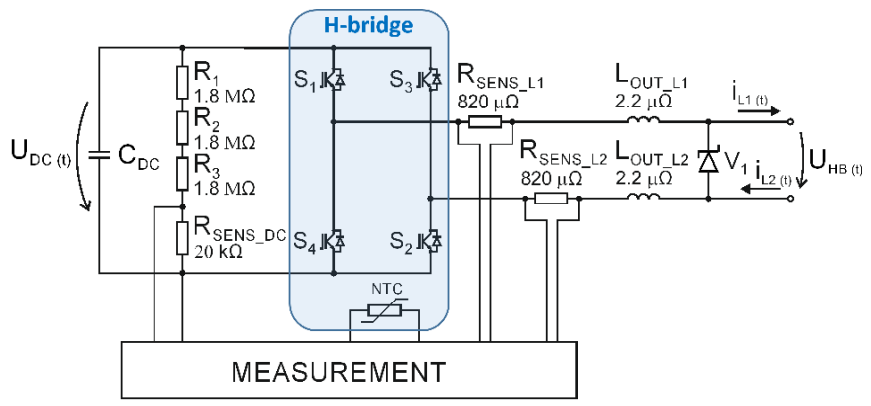

Fig. 3. Detailed H-bridge module scheme with measurement

The power block further contains power semiconductors protection, and signal and power connectors. The signal connectors are intended for the driver module. The power connectors create interconnection with the back panel. The power outputs of $\mathrm{H}$-bridge module are protected by a power transil $\mathrm{V}_{1}\left(825 \mathrm{~V}_{\mathrm{DC}}\right)$. The power outputs of the H-bridge contain sensing resistors $\mathrm{R}_{\text {SENS_L1 }}, \mathrm{R}_{\mathrm{SENS}_{\mathrm{L}} 2}$ for measurement of output current and output inductors $\mathrm{L}_{\mathrm{OUT}} \mathrm{L} 1$, L $\mathrm{L}_{\mathrm{OUT}} \mathrm{L} 2$ for minimization of extreme output current peaks. The resistors in dc-link creates voltage divider for $\mathrm{U}_{\mathrm{DC}}$ measurement.

\section{B. Driver module}

The driver module separates the high voltage and low voltage parts of the converter. Insulation of these two parts is reached using a dual IGBT driver. (Infineon 2ED020I12FA) and gate drive DC-DC converters (Murata MGJ1D241505MP). The driver module creates excitation signals for individual transistors and ensures desaturation protection. The driver module is interconnected with the power block using precise pin header connectors located in the high voltage part of the driver module. The position of these connectors respects insulation requirements among signals for individual transistors. The signal connectors for bottom $\mathrm{H}$ bridge transistors can be close to each other because of their same potential. Besides, the position of individual connectors is asymmetric. This placement excludes the wrong driver module connection. The front and rear side of the designed driver module is shown in Fig. 4.
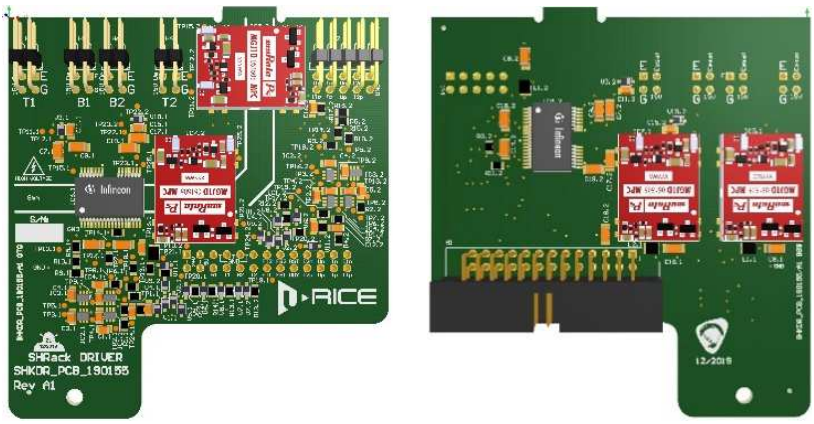

Fig. 4. Driver module

The driver enables two modes of IGBT control (using a single or dual signal [11]) but does not allow dead times for complementary IGBTs. Therefore, a dead-time hardware block is also proposed (Fig. 5).

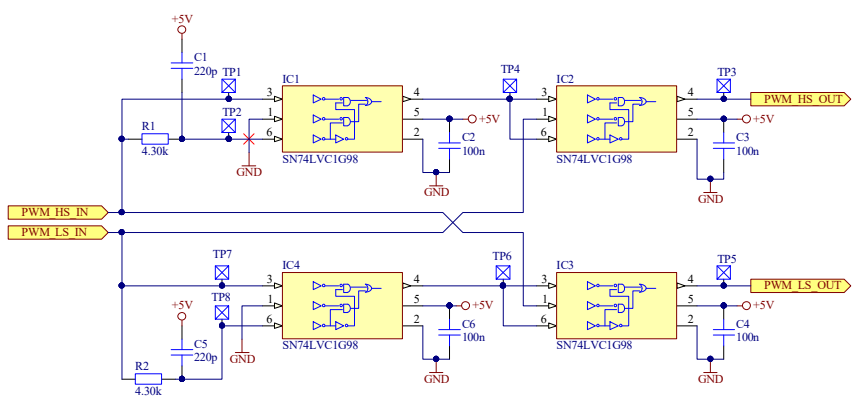

Fig. 5. Hardware dead times circuits

\section{Front panel board}

The front panel board creates the interface between a external control system and the power electronics. The designed board is split into four sections which correspond with the individual power blocks. The front panel of SHRack converter is shown in Fig. 6.

An installed microprocessor TMS320F28030 Piccolo evaluates fault signals from drivers and all measured physical quantities and ensures software protections. There is a possibility of user setting of the current, voltage and temperature limits. The software protections are individual for every power card. If any fault occurs, it causes all transistors are turned off.

An external control system can be connected to SHRack via D-SUB connectors. Every power board (channel) has one 16 pins D-SUB male connector for input control signals and one output 16 pins D-SUB female connector with all measured quantities in the differential signals form.

The front panel board is also equipped by CAN bus. All measured or fault data can be shared with other devices using this bus, and it can also set the internal parameters. A rotation switch located on the front panel above the CAN connector can be used to set the address of each SHRack. 
Measured currents, voltage, or temperature of the IGBT module can be shown on segment displays also placed on the front panel. The display can show other quantities as CAN address, help menu, or fault number.

The front panel contain drawn schemes of individual Hbridges combined with status LEDs. Thanks to them, it is easier to see the status of the individual H-bridges. Presence of status signals, switching combination of H-bridge or fault state of individual transistors can be easily detected.

The LED indicators on the right of the display show fault signal, ready signal, and actual physical quantity shown on display. The shown values can be changed using a switch, which is located next to the LED indicators.

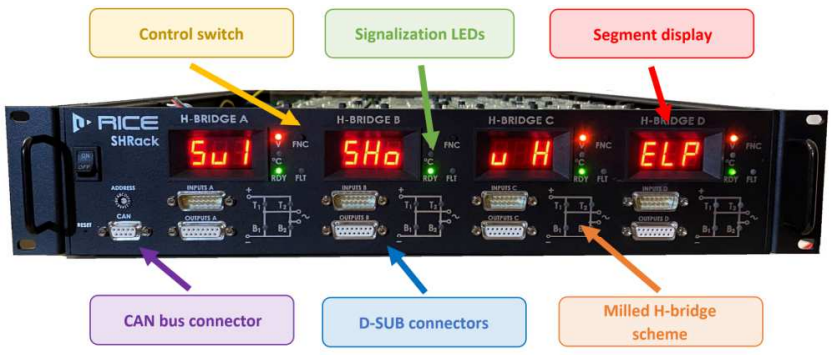

Fig. 6. Front panel

\section{Back panel board}

The back panel board creates the interface between the power part of the converter and other external power circuits (e.g. load). The back panel contains fuses, which protect the dc-link against a short circuit. Both poles of each dc-link bar are protected. The back panel board uses press-fit terminals to connect the dc-link and output power signals from each power block card. Special power cables, which have high bending ability, are used for interconnection.

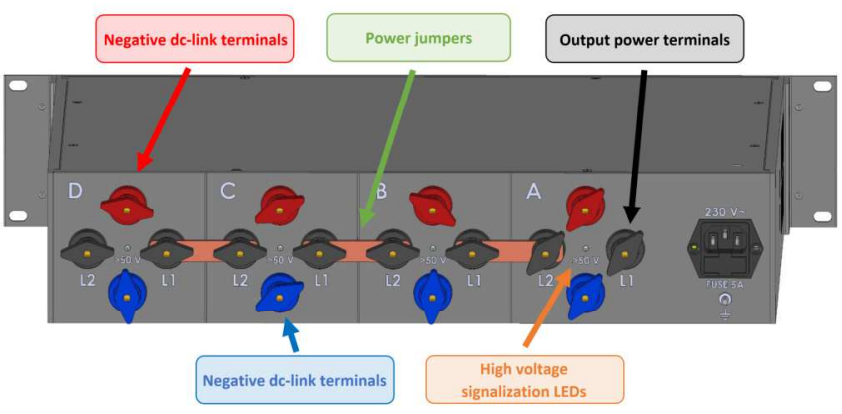

Fig. 7. Back panel

The power terminals with high insulation density are assembled in the back panel (see Fig. 7). The individual dclinks of all H-bridge converters are connected to the red and blue terminals. The power outputs of individual H-bridges are connected to the black L1 and L2 terminals. The placement of power terminals enables simple interconnection of inner $\mathrm{H}$ bridge converters. The parallel or cascaded topology can be created using special power jumpers. Power jumpers for cascaded connection of all H-bridges are indicated in Fig. 8. It corresponds with the configuration shown in Fig. 7. The back panel is further equipped with a signalization LED. This LED indicates that dc-link voltage is in a range from $50 \mathrm{~V}$ up to $900 \mathrm{~V}$. This signalization is implemented to all dc-link bars.

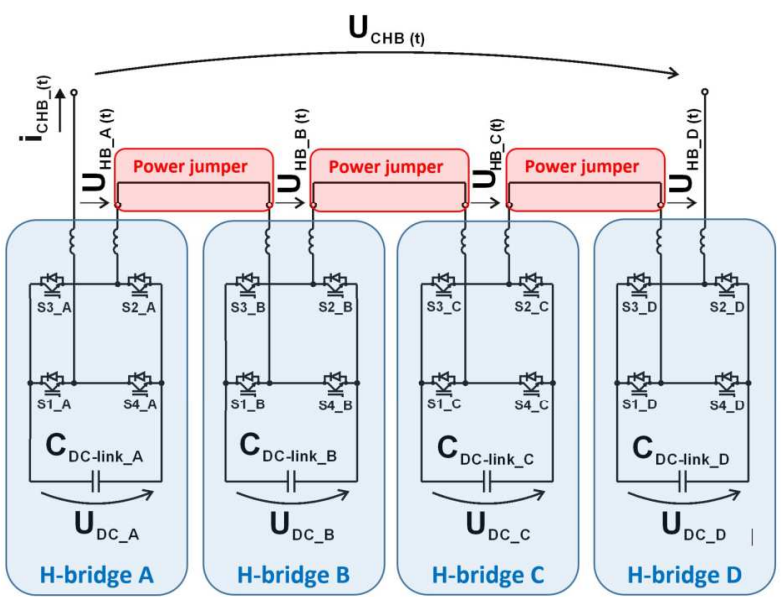

Fig. 8. Cascaded connection of all inner H-bridge modules

\section{E. Mechanical design}

The SHRack mechanical conception is designed to fit into a standard 19" rack mount. All components are designed concerning a $2 \mathrm{U}(88.9 \mathrm{~mm})$ rack-mounted enclosure. It brings advantages as simple mechanical connection and replacement, modularity, configurability, and scalability using parallel or serial installation of several converters. Also, the rack-mount enclosure improves EMC interference of the electrical device [10].

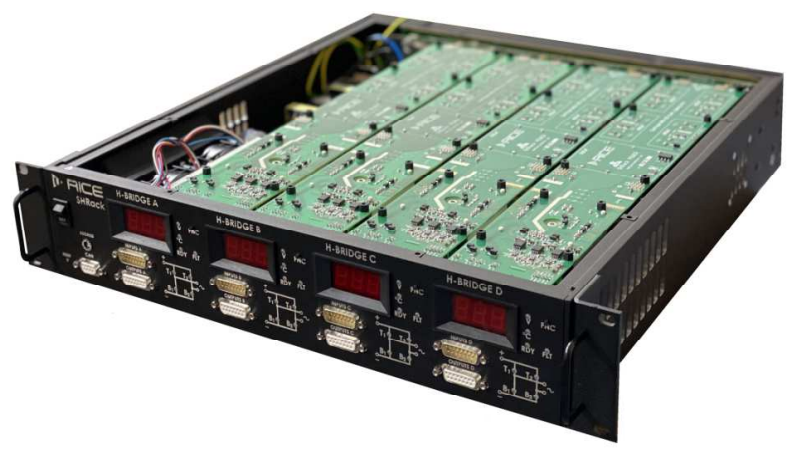

Fig. 9. Universal multi H-bridge converter (SHRack)

The SHRack converter mechanical design with all significant parts (power blocks, driver modules, front and back panels) without the top cover is shown in Fig. 9. The standard 2U height 19" Hammond manufacturing rack-mount enclosure is used as a mechanical base. This rack enclosure fulfills design requirements like load capacity, disassemble all parts ability, and EMC parameters. The individual parts of the proposed rack enclosure are made of aluminum type 5050 H32. The shape of the front, back, and both side panels fulfill PCB board implementation ability. The proposed mechanical conception allows disassembling of the whole converter to the individual parts. It allows simple testing, repairing, and changing of individual components.

\section{CONVERTER FEATURES AND PARAMETERS}

The proposed universal multi H-bridge converter was developed mainly for design and testing power converters modular multilevel topologies. Nevertheless, the SHRack converter can be used in applications as a single H-bridge motor drive, one phase active rectifier, 1-phase up to 8-phase 2-level converter, and single step-down or step-up converter.

The SHRack unit fulfills $1 \mathrm{kV}$ insulation. The individual $\mathrm{H}$-bridge converters can work with maximal current of $35 \mathrm{~A}$ 
RMS. The maximum dc-link voltage is $800 \mathrm{~V}$ per one power block (H-bridge module). In case of modular or cascaded topologies, the sum of individual dc-link voltages cannot exceed $1 \mathrm{kV}$. There is an insulation limit between the high voltage electrical part and the chassis of the converter. The maximum switching frequency is $20 \mathrm{kHz}$. The heatsink is shared for all power modules; therefore, the nominal power of the converter is $20 \mathrm{~kW}$ for four cascaded H-bridge modules, but one individual $\mathrm{H}$-bridge module can be operated with power of more than $5 \mathrm{~kW}$ (up to $10 \mathrm{~kW}$ with maximum switching frequency of $20 \mathrm{kHz}$ ).

\section{EXPERIMENTAL EVIDENCE}

In Fig. 10., there are shown SHRack converters during the experiments.

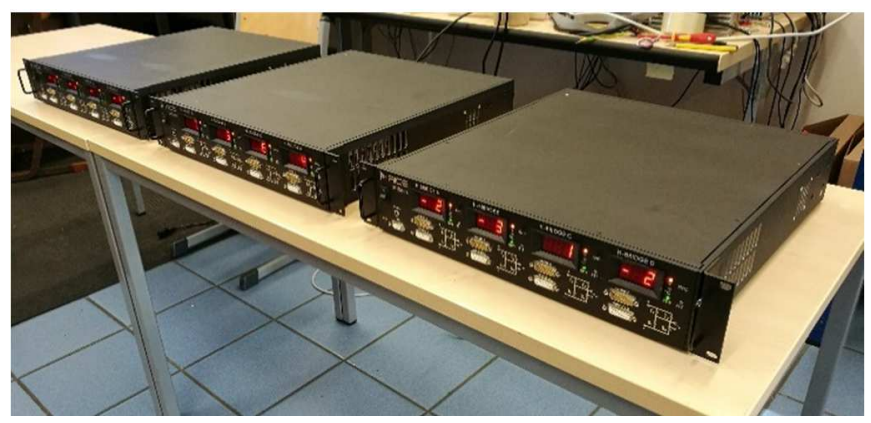

Fig. 10. SHRack converter first test

The experiment was performed on the laboratory STATCOM stand [8]. There were used three delta-connected SHRack converters. Four H-bridge modules in each SHRack were connected in cascade. So, one SHRack represents 9-level CHB topology (as shown in Fig. 8).

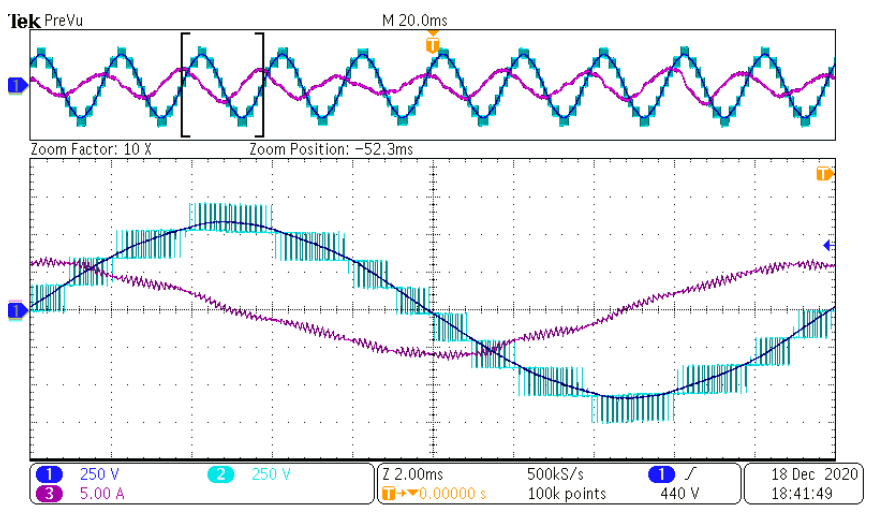

Fig. 11. Measurement of output voltage and current in case of cascaded inner H-bridge connection in SHRack converter

In Fig. 11, there are shown waveforms of the output voltage (blue) and the grid current (purple). It was measured on cascaded connection all inner H-bridge modules of the SHRack converter. The individual DC-link bars of H-bridge modules were charged to $180 \mathrm{~V}$. Therefore, the maximum output voltage was $720 \mathrm{~V}$. The current trough four cascaded H-bridge modules was 4.6 A RMS.

\section{CONCLUSION}

The new universal multi H-bridge converter (SHRack) has been introduced in this paper. The hardware conception is designed to fit standard $2 \mathrm{U}$ height 19 " rack enclosures. The SHRack design enables fast configuration of modular multilevel converter topology with the backup of all needed measurements and protections for complete testing procedures.

\section{ACKNOWLEDGMENT} 021.

This research has been supported by project SGS-2021-

\section{REFERENCES}

[1] C. Buccella, M. G. Cimoroni, M. Tinari and C. Cecati, "Seven-level cascaded inverters for Uninterruptible Power Supply (UPS) applications," IECON 2019 - 45th Annual Conference of the IEEE Industrial Electronics Society, Lisbon, Portugal, 2019, pp. 1549-1554, doi: 10.1109/IECON.2019.8927243.

[2] I. Sanz, M. Moranchel, E. J. Bueno and F. J. Rodríguez, "Nine-levels cascaded H-bridge converter prototype for FACTS applications," 2016 IEEE 7th International Symposium on Power Electronics for Distributed Generation Systems (PEDG), Vancouver, BC, Canada, 2016, pp. 1-4, doi: 10.1109/PEDG.2016.7527058.

[3] Z. Wang, H. Lin, Y. Ma and T. Wang, "A prototype of modular multilevel converter with integrated battery energy storage," 2017 IEEE Applied Power Electronics Conference and Exposition (APEC), Tampa, FL, USA, 2017, pp. 434-439, doi: 10.1109/APEC.2017.7930730.

[4] J. Yu, R. Burgos, N. R. Mehrabadi and D. Boroyevich, "Design of a SiC-based modular multilevel converter for medium voltage DC distriution system," 2017 IEEE Applied Power Electronics Conference and Exposition (APEC), Tampa, FL, USA, 2017, pp. 467-473, doi: 10.1109/APEC.2017.7930735.

[5] G. Konstantinou, S. Ceballos, I. Gabiola, J. Pou, B. Karanayil and V. G. Agelidis, "Flexible prototype of modular multilevel converters for experimental verification of DC transmission and multiterminal systems," 2017 Asian Conference on Energy, Power and Transportation Electrification (ACEPT), Singapore, 2017, pp. 1-6, doi: 10.1109/ACEPT.2017.8168595.

[6] Y. Zhou, D. Jiang, P. Hu, J. Guo, Y. Liang and Z. Lin, "A Prototype of Modular Multilevel Converters," in IEEE Transactions on Power Electronics, vol. 29, no. 7, pp. 3267-3278, July 2014, doi: 10.1109/TPEL.2013.2278338.

[7] M. Moranchel, F. M. Sanchez, E. J. Bueno, F. J. Rodriguez and I. Sanz, "Six-level modular multilevel converter prototype with centralized hardware platform controller," IECON 2015 - 41st Annual Conference of the IEEE Industrial Electronics Society, Yokohama, Japan, 2015, pp. 003863-003868, doi: 10.1109/IECON.2015.7392702.

[8] M. V. Blahnik, M. Straka and M. Pittermann, "Analysis of Multilevel Electronic Balancer for AC Traction Substation with PS-PWM," 2020 International Conference on Applied Electronics (AE), Pilsen, Czech Republic, 2020, pp. 1-4, doi: 10.23919/AE49394.2020.9232778.

[9] Z. Kehl, T. Glasberger and Z. Peroutka, "Finite Control Set Model Predictive Control of Static Compensator," 2019 IEEE 28th International Symposium on Industrial Electronics (ISIE), Vancouver, BC, Canada, 2019, pp. 858-863, doi: 10.1109/ISIE.2019.8781514.

[10] T. Glasberger, Z. Kehl, T. Kosan and J. Molnar, "Design of modular low-profile frequency converter for multi-motor manipulators," 2020 22nd European Conference on Power Electronics and Applications (EPE'20 ECCE Europe), Lyon, France, 2020, pp. P.1-P.6, doi: 10.23919/EPE20ECCEEurope43536.2020.9215783.

[11] INFINEON, Datasheet 2ED020I12FA Dual IGBT Driver IC [Online]. Available: https://www.infineon.com/dgdl/Infineon-2ED020I12FADS-v03_01-EN.pdf?fileId=db3a30432e779412012e7b87d2b23878 